\title{
THE STATIC SUBSTRUCTURE METHOD FOR DYNAMIC ANALYSIS OF STRUCTURES
}

\author{
Lou Menglin*
}

\begin{abstract}
SUMMARY
In this paper, the static substructure method based on the Ritz vector direct superposition method is suggested for analyzing the dynamic response of structures. The advantage of this algorithm is that the computer cost can be reduced and the static analysis and the dynamic analysis of large structures can be simplified by using the identical static substructure method.
\end{abstract}

\section{INTRODUCTION}

Recently, the dynamic substructure mode synthesis method (1-6) was developed for dynamic analysis of large structures. Although there are many different algorithms for the dynamic substructure method, the principle of them all is similar. In general, the total system is divided into several substructures and a smaller eigenvalue problem is solved for each substructure. Then, by truncating the higher modes, the lowest mode shapes or pseudo-static displacements of the substructure are used to form the Ritz vectors of the total system. The size of the total system is reduced significantly by using these Ritz vectors. As several smaller eigenvalue problems are evaluated instead of evaluation of a large eigenvalue problem, the dynamic substructure method can reduce the computer cost and computer storage required. The dynamic substructure method is based on the modal superposition method.

If the dynamic substructure method is used for dynamic analysis of large structures, the following shortcomings exist:

1. Solution for a set of eigenvalue problems of the substructures is still expensive, especially for large structures.

2. The error produced by truncating higher modes of substructure cannot be avoided.

The purpose of this paper is to propose a new substructure method. When this method is applied to the dynamic analysis of structures, the solution of a set of algebraic equations is required instead of a solution of an eigenvalue problem in the substructure and the shortcomings mentioned above do not exist.

TWO METHODS FOR LINEAR DYNAMIC ANALYSIS OF OF STRUCTURES

Dalian Institute of Technology, Dalian, P.R. China.
The dynamic equilibrium equation for a structure, modelled by a finite number of discrete members and lumped masses, is written in terms of joint displacements as

$[M]\{\ddot{\mathrm{u}}(t)\}+[C]\{\dot{\mathrm{u}}(\mathrm{t})\}+[\mathrm{K}]\{\mathrm{u}(\mathrm{t})\}=\{\mathrm{P}(\mathrm{t})\}$

where [M], [C] and [K] are the given $(n \times n)$ mass, damping and stiffness matrices. The time-dependent vectors $\{\ddot{u}(t)\},\{\dot{u}(t)\}$ and $\{u(t)\}$ are the joint accelerations, velocities and displacements respectively. If the time-varying load can be further factored into a sum of space vectors multiplied by time functions, Eq. (1) can be written as

$[M]\{\ddot{u}(t)\}+[C]\{\dot{u}(t)\}+[K]\{u(t)\}=\{f\} g(t)$

For linear structures, the displacements vector $u(t)$ can be approximately expressed by linear superposition of several orthogonal base vectors

$$
\begin{aligned}
\{u(t)\} & =\sum_{j=1}^{m}\left\{t_{j}\right\} q_{j}(t) \\
& =[T]\{q(t)\}
\end{aligned}
$$

where $\{\mathrm{q}(t)\}$ is an array of $m$ unknown time functions and [T] is a (nxm) matrix.

The substitution of Eq. 3 into Eq. 2 and the premultiplication by [T] $]^{\mathrm{T}}$ yields

$$
\begin{aligned}
{\left[M^{*}\right]\{q(t)\}+\left[C^{*}\right]\{\dot{q}(t)\} } & +\left[K^{*}\right]\{q(t)\} \\
& =\{f *\} g(t)
\end{aligned}
$$

in which

$$
\begin{aligned}
& {\left[M^{*}\right]=[T]^{T}[M][T]} \\
& {\left[C^{*}\right]=[T]^{T}[C][T]} \\
& {\left[K^{*}\right]=[T]^{T}[K][T]} \\
& \{f *\}=[T]^{T}\{f\}
\end{aligned}
$$

When $\mathrm{m}<<\mathrm{n}$, solution of Eq. (2) can be simplified significantly. 
For linear analysis, the transformation matrix [T] can be obtained by two methods.

\section{The Model Superposition Method}

This is a well known method for dynamic analysis of structures. The matrix [T] is generated by solving the following eigenvalue problem:

$$
\left([\mathrm{K}]-\lambda_{j}[\mathrm{M}]\right)\left\{t_{j}\right\}=\{0\} . \quad(j=1,2, \ldots, \mathrm{m})
$$

The matrix [T] is the assembly of the lowest eigenvectors of the system. The matrix [M*] and $\left[\mathrm{K}^{*}\right]$ are both diagonal. If proportional damping is assumed, the matrix $\left[\mathrm{C}^{*}\right]$ is also diagonal. Therefore, Eq. (4) is reduced to a set of uncoupled, linear, second-order, ordinary differential equations.

However, solving for the eigenvalue in Eq. (6) is expensive for large structures with hundreds or thousands degrees of freedom.

\section{Ritz Vectors Direct Superposition Method (R-method)}

Recently, E.L. Wilson et al (7) suggested a new approach to generate the matrix [T]. The main steps of this method are described as follows:

(1) Solve for the first vector $\left\{x_{1}\right\}$

$$
\begin{aligned}
& {[\mathrm{k}]\left\{\mathrm{y}_{1}\right\}=\left\{\mathrm{f}_{1}\right\}} \\
& \left\{\mathrm{x}_{1}\right\}=\mathrm{a}_{1}\left\{\mathrm{y}_{1}\right\}
\end{aligned}
$$

in which

$$
\begin{gathered}
\left\{\mathrm{f}_{1}\right\}=\{\mathrm{f}\} \\
\left.\left.\mathrm{a}_{1}=\left({\left\{\mathrm{y}_{1}\right.}\right\}^{\mathrm{T}}[\mathrm{M}] \mathrm{y}_{1}\right\}\right)^{-0.5}
\end{gathered}
$$

(2) Solve for additional vectors $\left\{\mathrm{x}_{\mathrm{k}}\right\}(\mathrm{k}=1$,

$$
2, \ldots, m)
$$

$$
\begin{gathered}
{[\mathrm{K}]\left\{\mathrm{y}_{\mathrm{k}}\right\}=\left\{\mathrm{f}_{\mathrm{k}}\right\}} \\
\left\{\mathrm{x}_{\mathrm{k}}^{*}\right\}=\left\{\mathrm{y}_{\mathrm{k}}\right\}-\sum_{j=1}^{\mathrm{k}-1} \mathrm{c}_{\mathrm{kj}}\left\{\mathrm{x}_{\mathrm{j}}\right\} \\
\left\{\mathrm{x}_{\mathrm{k}}\right\}=\mathrm{a}_{\mathrm{k}}\left\{\mathrm{x}_{\mathrm{k}}^{*}\right\}
\end{gathered}
$$

in which

$$
\begin{gathered}
\left\{\mathrm{f}_{\mathrm{k}}\right\}=[M]\left\{\mathrm{x}_{\mathrm{k}-1}\right\} \\
\mathrm{c}_{\mathrm{kj}}=\left\{\mathrm{y}_{\mathrm{k}}\right\}^{\mathrm{T}}[\mathrm{M}]\left\{\mathrm{x}_{j}\right\} \\
\mathrm{a}_{\mathrm{k}}=\left(\left\{\mathrm{x}_{\mathrm{k}}^{*}\right\}^{\mathrm{T}}[\mathrm{M}]\left\{\mathrm{x}_{\mathrm{k}}^{*}\right\}\right)-0.5
\end{gathered}
$$

(3) Reduce the stiffness matrix of the total system

$$
[\tilde{\mathrm{K}}]=[\mathrm{X}]^{\mathrm{T}}[\mathrm{K}][\mathrm{X}]
$$

(4) Solve the generalized eigenvalue problem

$$
\left([\tilde{K}]-\lambda_{j}[I]\right)\left\{z_{j}\right\}=\{0\} \quad(j=1,2, \ldots, m)
$$

(5) Obtain the matrix [T]

$$
[\mathrm{T}]=[\mathrm{X}][\mathrm{Z}]
$$

As the R-method turns evaluation of the eigenvalue equation into a set of evaluation of the algebraic equations, the computer cost can be reduced.

The new substructure method presented in this paper is based on the R-method.

\section{THE STATIC SUBSTRUCTURE METHOD}

In the R-method, the main effort lies in evaluating the set of algebraic equations (7) and (9), which can be written in a unified form

$$
[\mathrm{K}]\{\mathrm{y}\}=\{\mathrm{f}\}
$$

when $\{y\}$ indicates $\left\{y_{k}\right\},\{f\}$ indicates $\left\{f_{k}\right\}$ such as Eq. (7) and Eq. (9).

A static substructure method is suggested for solving Eq. (18) to reduce the computer cost and computer store for large structures. The principle of the method is described as follows.

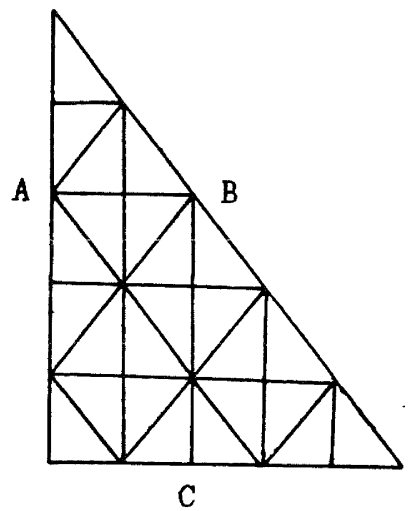

FIG. 1 - TRIANGULAR CROSS SECTION OF GRAVITY DAM AND ITS DIVISION OF SUBSTRUCTURES

The cross section of gravity dam shown in Fig. 1 is divided into three substructures by the common boundaries $A B$ and $B C$. The joints on the common boundaries $A B$ or $\mathrm{BC}$ are called boundary joints and the other joints which are free are called internal joints. The variables referring to boundary joints or internal joints are denoted by subscripts "B" or "I" respectively. The procedure of the static method is summarized as follows:

1. Generate the mass and stiffness matrix for each substructure

$$
\begin{aligned}
& {\left[K^{(i)}\right]=\left[\begin{array}{ll}
K_{I I}^{(i)} & K_{I B}^{(i)} \\
K_{B I}^{(i)} & K_{B B}^{(i)}
\end{array}\right]} \\
& {\left[M^{(i)}\right]=\left[\begin{array}{ll}
M_{I I}^{(i)} & 0 \\
0 & M_{B B}^{(i)}
\end{array}\right]}
\end{aligned}
$$

in which, superscript " $i$ " indicates the $i^{\text {th }}$ substructure.

2. Condense $\left[\mathrm{K}^{(\mathrm{i})}\right]$ to the boundary joints to form the condensed stiffness matrix 
$\left[\bar{K}^{(i)}\right]$ of the $i^{\text {th }}$ substructure.

$$
\left[\bar{K}^{(i)}\right]=\left[K_{B B}^{(i)}\right]-\left[K_{B I}^{(i)}\right]\left[K_{I I}^{(i)}\right]^{-1}\left[K_{I B}^{(i)}\right]
$$

3. Assemble $\left[\overline{\mathrm{K}}^{(i)}\right]$ into the total condensed stiffness matrix $[\bar{K}]$ of the system, according to the order of DOF of boundary joints.

$$
[\overline{\mathrm{K}}] \Leftarrow\left[\overline{\mathrm{K}}^{(\mathrm{i})}\right]
$$

4. Calculate the condensed load vector for each substructure and assemble them to form the total condensed load vector $\left\{\bar{f}_{B}\right\}$ of the system

$$
\begin{gathered}
\left\{\bar{f}_{B}^{(i)}\right\}=\left\{f_{B}^{(i)}\right\}-\left[K_{B I}^{(i)}\right]\left[K_{I I}^{(i)}\right]^{-1}\left\{f_{I}^{(i)}\right\} \\
\left\{\bar{f}_{B}\right\}=\left\{\bar{f}_{B}^{(i)}\right\}
\end{gathered}
$$

5. Calculate the displacements of the boundary joints under the load

$$
\left\{\mathrm{y}_{\mathrm{B}}\right\}=[\overline{\mathrm{K}}]^{-1}\left\{\overline{\mathrm{f}}_{\mathrm{B}}\right\}
$$

6. Calculate the displacements of the internal joints of each substructure

$$
\begin{gathered}
\left\{y_{I}^{(i)}\right\}=\left[K_{I I}^{(i)}\right]^{-1}\left\{f_{I}^{(i)}\right\}-\left(\left[K_{B I}^{(i)}\right]\left[K_{I I}^{(i)}\right]^{-1}\right)^{T} \\
\left\{y_{B}^{(i)}\right\}
\end{gathered}
$$

After finishing step 1 to step 4 for each
substructure, [ $\mathrm{K}(\mathrm{i})][\mathrm{K}(\mathrm{i})]^{\mathrm{I}}$ and $[\mathrm{K}(\mathrm{i})]^{-1}$

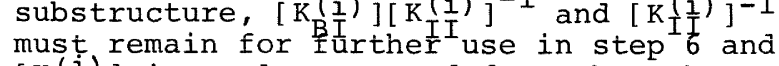
$[\mathrm{K}(\mathrm{i})$ ] is no longer needed so that the requirements for computer storage are reduced.

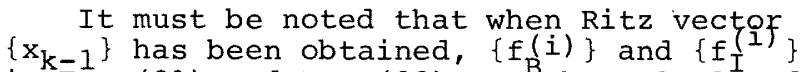
in $\mathrm{Eq}$. (21) and Eq. (23) must be calculated as follows:

$$
\begin{aligned}
& \left\{f_{B}^{(i)}\right\}=\left[M_{B B}^{(i)}\right]\left\{x_{B}^{(i)}\right\} \\
& \left\{f_{I}^{(i)}\right\}=\left[M_{I I}^{(i)}\right]\left\{x_{I}^{(i)}\right\}
\end{aligned}
$$

in which $\left\{\mathrm{x}_{\mathrm{I}}^{(i)}\right\}$ and $\left\{\mathrm{x}_{\mathrm{B}}^{(i)}\right\}$ are displacements of internal and boundary joints of the $i^{\text {th }}$ substructure in $\left\{\mathrm{x}_{\mathrm{k}-1}\right\}$.

As the stiffness matrix of each substructure is not available to assemble the stiffness matrix of the total system, the reduced stiffness matrix [K] of the total system cannot be formed from Eq. (15), but it can be generated in another way. Let

$$
\left\{\mathrm{p}_{\mathrm{k}}\right\}=[\mathrm{k}]\left\{\mathrm{x}_{\mathrm{k}}\right\}
$$

The vector $\left\{p_{k}\right\}$ is an elastic force vector of the structure which makes the structure deform as $\left\{x_{k}\right\}$. Due to the recurrence relationship between the Ritz vectors $\left\{\mathrm{x}_{\mathrm{k}}\right\} \quad(\mathrm{k}=1,2, \ldots, \mathrm{m})$, a recurrence relationship between $\left\{\mathrm{p}_{\mathrm{k}}\right\}$ exists too. According to Eq. 24 and Eqs. $(7,8)$ or Eqs. $(9-11),\left\{p_{1}\right\}$ and $\left\{p_{2}\right\}$ can be written as

$$
\begin{aligned}
\left\{\mathrm{p}_{1}\right\} & =[\mathrm{k}]\left\{\mathrm{x}_{1}\right\} \\
& =[\mathrm{k}]\left(\mathrm{a}_{1}\left\{\mathrm{y}_{1}\right\}\right) \\
& =a_{1}\left\{\mathrm{f}_{1}\right\}
\end{aligned}
$$

$$
\begin{aligned}
p_{2} & =[k]\left\{x_{2}\right\} \\
& =[k]\left(a_{2}\left\{x_{2}\right\}\right) \\
& =a_{2}\left([K]\left\{y_{2}\right\}-c_{21}[K]\left\{x_{1}\right\}\right) \\
& =a_{2}\left(\left\{f_{2}\right\}-c_{21}\left\{p_{1}\right\}\right)
\end{aligned}
$$

Similarly, the recurrence relationship can be expressed as

$$
\begin{aligned}
\left\{\mathrm{p}_{\mathrm{k}}\right\} & =[\mathrm{k}]\left\{\mathrm{x}_{\mathrm{k}}\right\} \\
& =\mathrm{a}_{\mathrm{k}}\left(\left\{\mathrm{f}_{\mathrm{k}}\right\}-\sum_{j=1}^{\mathrm{k}-1} \mathrm{c}_{\mathrm{kj}}\left\{\mathrm{x}_{\mathrm{j}}\right\}\right)
\end{aligned}
$$

Eq. (29) indicates that $\left\{\mathrm{p}_{\mathrm{k}}\right\}$ is concerned with previous force vectors $\left\{\mathrm{p}_{1}\right\}$ to $\left\{p_{k-1}\right\}$ and also with the load $\left\{f_{k}\right\}$. After the Ritz vector $\left\{\mathrm{x}_{\mathrm{k}}\right\}$ is generated, the $\left\{\mathrm{p}_{\mathrm{k}}\right\}$ should be calculated immediately by Eq. (27). Thus, Eq. 15 becomes

$$
\begin{aligned}
{[\mathrm{K}] } & =\left[\mathrm{x}_{1}, \mathrm{x}_{2}, \ldots, \mathrm{x}_{\mathrm{m}}\right]\left[\mathrm{p}_{1}, \mathrm{p}_{2}, \ldots, \mathrm{p}_{\mathrm{m}}\right] \\
& =[\mathrm{X}]^{\mathrm{T}}[\mathrm{P}]
\end{aligned}
$$

In the static substructure method, the order of the reduced stiffness matrix [ $\tilde{K}]$ is only dependent on the number of Ritz vectors and is independent of the number of DOF of the boundary between substructures.

\section{APPLICATIONS}

Two examples are solved to illustrate the application of the static substructure method for dynamic analysis of structures.

\section{Simple Shear Building}

The building shown in Fig. $2 \mathrm{a}$ is simplified as a shear cantilever model with lumped mass. For simplification, it is assumed that all spring factors $k$ and lumped mass $m$ are equal to unity.

Four methods were adopted and compared with each other:

Method A: the static substructure method presented in this paper. The model was divided into four substructures as shown in Fig. 2b. Three Ritz vectors were generated $(m=3)$. The calculation was not performed by computer.

Method B: the dynamic substructure method (non-interface method for substructural mode synthesis (5)). The model was divided into two substructures as shown in Fig. 2c. Two modes were taken for each substructure. Four Ritz vectors were generated $(m=4)$.

Method $\mathrm{C}$ : the dynamic substructure method (Craig's constrained mode method (2)). The model was divided into two substructures as shown in Fig. 2d. One mode was taken for each substructure. Including one pseudostatic displacement vector, three Ritz vectors were generated $(m=3)$.

Method D: Craig's constrained mode method. The model was also divided into four substructures as shown in Fig. $2 \mathrm{~b}$. One mode was taken for each substructure. Including three pseudo-static displacement vectors, 

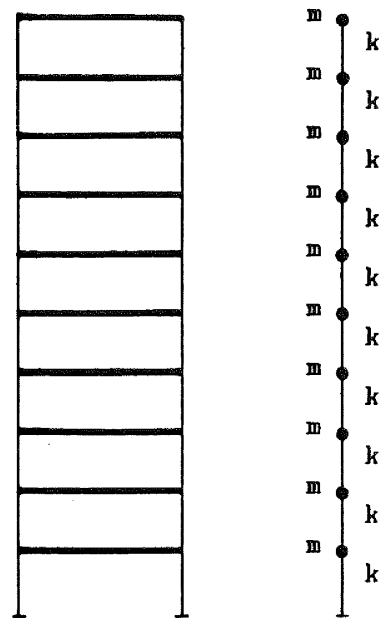

(a)

(b)
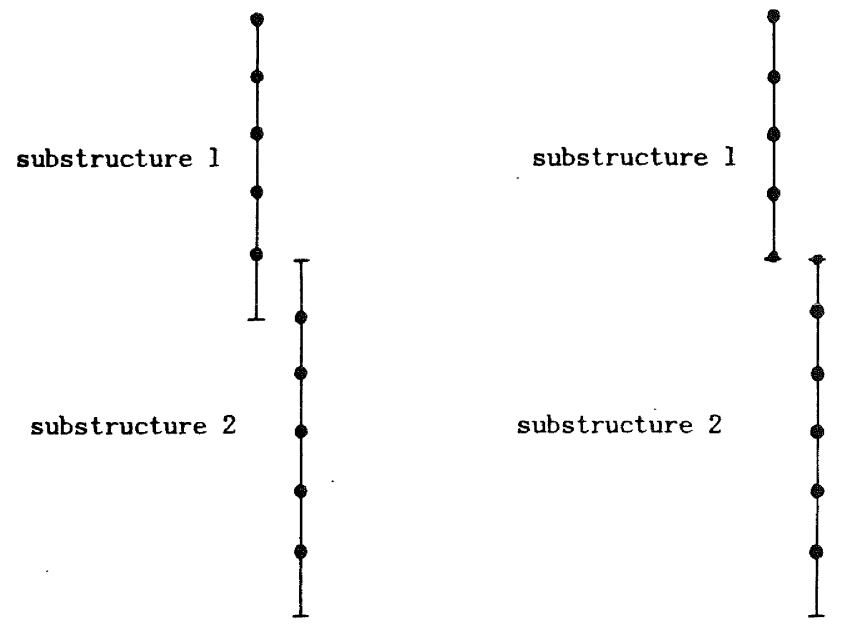

(c)

(d)

FIG. 2 - SIMPLE SHEAR BUILDING AND ITS DIVISION OF SUBSTRUCTURES

seven Ritz vectors were generated $(m=7)$.

The exact frequencies and the approximate frequencies of the system by using four substructure algorithms are given in Table 1.

TABLE 1 - FIRST THREE FREQUENCIES OF THE BUILDING

\begin{tabular}{|l|c|c|c|c|c|}
\hline Mode & exact & $\begin{array}{c}\text { method } \\
\text { A }\end{array}$ & $\begin{array}{c}\text { method } \\
\text { B }\end{array}$ & $\begin{array}{c}\text { method } \\
\text { C }\end{array}$ & $\begin{array}{c}\text { method } \\
\text { D }\end{array}$ \\
\hline 1 & 0.1495 & 0.1495 & 0.3473 & 0.2382 & 0.1495 \\
2 & 0.4450 & 0.4456 & 0.5176 & 0.4918 & 0.4455 \\
3 & 0.7307 & 0.8387 & 0.6882 & 0.7808 & 0.7355 \\
\hline
\end{tabular}

This example shows that the static substructure method possesses higher precision and needs less computation than the dynamic substructure method as the number of Ritz vectors is the same.

\section{Two-Dimensional Concrete Gravity Dam}

A triangular cross section of concrete gravity dam was divided into three substructures as shown in Fig. 1. Its height was 100 metres and the width of its base was 80 metres. Table 2 gives a comparison of the frequencies obtained by the static substructure method and the subspace iteration method. When using ten Ritz vectors, the ratio of computer time needed for the two methods was about $1: 1.5$.

TABLE 2 - FIRST FIVE FREQUENCIES OF THE DAM $(\mathrm{Hz})$

\begin{tabular}{|c|c|c|}
\hline Mode & $\begin{array}{c}\text { The static } \\
\text { substructure method }\end{array}$ & $\begin{array}{c}\text { the subspace } \\
\text { iteration method }\end{array}$ \\
\hline 1 & 5.322 & 5.275 \\
2 & 11.893 & 11.846 \\
3 & 13.331 & 12.809 \\
4 & 21.552 & 20.227 \\
5 & 27.286 & 25.592 \\
\hline
\end{tabular}

\section{CONCLUSIONS}

The static substructure method is suggested for analyzing the dynamic response of the structures; it possesses three advantages:

\section{No algorithm error exists in the} analysis stage of the substructures as the static substructure method is in itself an accurate algorithm.

2. An eigenvalue problem does not occur in the analysis of the substructures, so the computer cost can be reduced.

3. The number of reduced eigenvalue equations for system is equal to the number of Ritz vectors and is independent of the number of DOF of the interface between the substructures. This is very meaningful in analyzing the dynamic response of massive structures such as arch dams.

When the Lanczos method (8) is used for the dynamic analysis of structures, its main work is also solving a set of algebraic equations. Consequently, the static substructure method could also be used.

\section{REFERENCES}

1. W.C. Hurty, 1965. "Dynamic analysis of structural systems using component modes", AIAA J. 3(4): 678:685.

2. R.R. Craig, Jr., and M.C.C. Bampton, 1968. "Coupling of substructures for dynamic analyses", AIAA J. 6(7) : 13131319 .

3. S. Rubin, 1975. "Improved componentmode representation for structural analysis", AIAA J. 13(8): 995-1006.

4. R.R. Craig, Jr. and C-J. Chang, 1977. "Substructure coupling for dynamic analysis and testing", NASA CR-2781.

5. R. Zhang and M. Dong, 1984. "Noninterface method for substructural mode synthesis", Computational structural Mechanics \& Applications (China) $1(3): 51-58$ 
6. Z. Ma and Y. Lu, 1985. "Taking 'residual stiffness' and 'residual mass' into consideration for free-interface method of component mode synthesis", Jnl. of Vibration and Shock (China) (3): 69-74.

7. E.L. Wilson et al, 1982. "Dynamic analysis by direct superposion of Ritz vectors", Earthquake Engineering and Structural Dynamics, 10(6): 813-821.

8. B. Nour-Omid and R.W. Clough, 1984.

"Dynamic analysis of structures using Lanczos co-ordinates", Earthquake and Structural Dynamics 12(4): 565-577. 